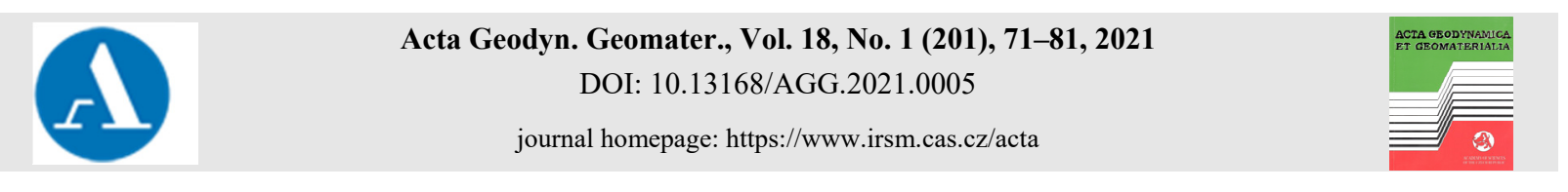

ORIGINAL PAPER

\title{
SHEAR MODULUS AND DAMPING RATIO OF CLAY SOIL UNDER REPEATED FREEZE-THAW CYCLES
}

\author{
Mahya ROUSTAEI ${ }^{1,2)}$ *, Michael HENDRY 2), \\ Eisa ALI AGHAEI ${ }^{1)}$ and Meysam BAYAT ${ }^{3)}$
}

\author{
1) Department of Civil Engineering, Qazvin Branch, Islamic Azad University, Qazvin, Iran \\ ${ }^{2)}$ Department of Civil and Environmental Engineering, University of Alberta, Edmonton, Alberta, Canada \\ ${ }^{3)}$ Department of Civil Engineering, Najafabad Branch, Islamic Azad University, Najafabad, Iran
}

*Corresponding author's e-mail: mroustae@ualberta.ca

\begin{tabular}{|c|c|}
\hline ARTICLE INFO & ABSTRACT \\
\hline Article history: & \multirow{10}{*}{$\begin{array}{l}\text { The dynamic properties of soil deposits subjected to dynamic loading, such as the shear modulus } \\
G \text { and material damping ratio } D \text {, are important parameters in ground response seismic analysis. In } \\
\text { seasonally frozen regions, these properties can be significantly affected by microstructural changes } \\
\text { that occur during freeze-thaw cycles. The current study evaluated the dynamic properties of clayey } \\
\text { soil exposed to freeze-thaw cycles. Dynamic triaxial testing was conducted to determine the } \\
\text { influence of mean effective consolidation stress, cyclic stress ratio, loading frequency, and } \\
\text { freeze-thaw cycles on } G-\gamma \text { and } D-\gamma \text { curves. Scanning electron microscopy (SEM) was carried out } \\
\text { to investigate microstructural changes in the clay soil fabric. The results indicate the freeze-thaw } \\
\text { process has an important effect on dynamic properties of the soil. The dynamic shear modulus } \\
\text { increases with increasing effective confining pressure, loading frequency, and confining pressure, } \\
\text { and decreases with increasing number of freeze-thaw cycles. Development of more voids between } \\
\text { clay particles after ice lens formation during these cycles results in an increase in the damping } \\
\text { ratio, but this trend decreases with increasing confining pressure. Increasing the loading frequency } \\
\text { increases or decreases the damping ratio depending upon the mean effective confining pressure } \\
\text { and number of freeze-thaw cycles. }\end{array}$} \\
\hline Received 17 August 2020 & \\
\hline Accepted 1 February 2021 & \\
\hline Available online 17 February 2021 & \\
\hline Keywords: & \\
\hline Shear modulus & \\
\hline Damping ratio & \\
\hline Freeze-thaw cycles & \\
\hline Confining stress & \\
\hline Loading frequency & \\
\hline
\end{tabular}

\section{INTRODUCTION}

Freeze-thaw cycles are a normal weathering phenomenon in cold climates that considerably change the structure and thus have a great influence on the engineering properties of soils (e.g., physical and mechanical features), which can also result in significant changes in dynamic properties. As soil moisture freezes, ice crystals form and the soil sample is subjected to a volumetric change of up to $9 \%$; this applies considerable stress to soil aggregates, resulting in changes in soil characteristics at the micro and macro scales (Dusenkova et al., 2013; Ghazavi and Roustaei, 2013; Konrad, 1989; Szostak-Chrzanowski and Chrzanowski, 2014).

The input parameters of soil materials for substructure seismic analysis and design include the maximum shear modulus $\left(G_{\max }\right)$, normalized stiffness $\left(G / G_{\max }\right)$, and damping ratio $(D)$ over a wide range of shear strains $(\gamma)$, and these influence the response of soil layers to dynamic loads such as earthquakes, waves, strong winds, and cyclic traffic loading. However, dynamic in situ tests cannot be carried out in most geotechnical investigations due to cost considerations and the lack of specialized personnel (Hanumantharao and Ramana, 2008). Most research is conducted using one or a combination of advanced laboratory testing techniques, e.g., bender element (Bayat and Ghalandarzadeh, 2020; Gu et al., 2015), resonant column (Bayat and Ghalandarzadeh, 2019; Senetakis and Payan, 2018), simple shear (Vucetic and Mortezaie, 2015) and cyclic triaxial testing (Bayat, 2020; Khan et al., 2011), that represent different levels of shear strain. However, the dynamic properties of clayey soil as a nonlinear material are affected by factors such as mean effective confining pressure, relative density, shear strain amplitude, geologic age, cementation, over-consolidation ratio, plasticity characteristics, cyclic strain, loading frequency, and the number of loading cycles (Hardin and Drnevich, 2002; Jafarian et al., 2014; Kokusho, 1980; Ng et al., 2016).

Recent studies have focused on the static strength, shear modulus or resilient modulus and damping ratio of frozen soil using wave propagation, dynamic triaxial, resonant column, and ultrasonic testing (Lin et al., 2018; Renliang et al., 2019; Wang et al., 2018; Zhang and Hulsey, 2015; Zhao et al., 2017). Temperature, shear strain amplitude, loading frequency, mean effective confining pressure, and relative density or water content influence the dynamic properties of frozen soil (Flora and Lirer, 2013; Wang et al., 2003; Zhao et al., 2017; Zhu et al., 


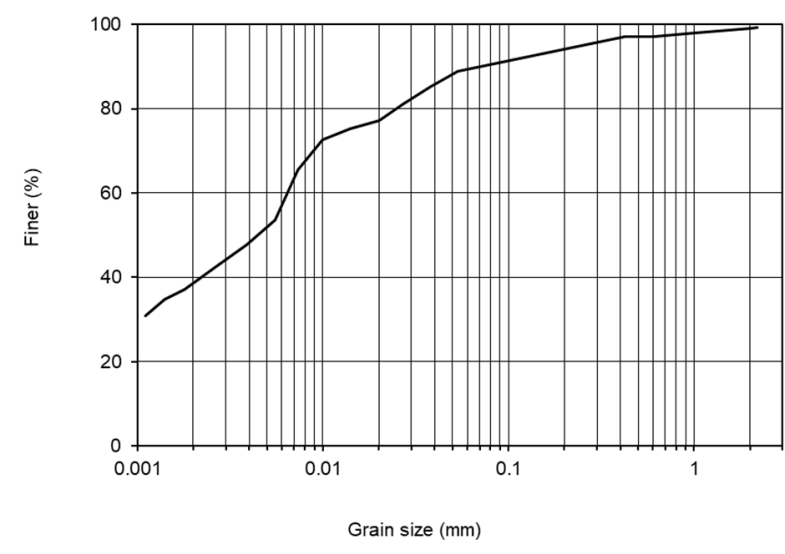

Fig. 1 Grain size distribution curves of Abyek clay.

Table 1 Chemical properties of Abyek clay.

\begin{tabular}{lc}
\hline Mineral composition & Weight portion (\%) \\
\hline $\mathrm{SiO}_{2}$ & 39.5 \\
$\mathrm{L.O} . \mathrm{I}$ & 17.11 \\
$\mathrm{CaO}$ & 15 \\
$\mathrm{Al}_{2} \mathrm{O}_{3}$ & 13.4 \\
$\mathrm{Fe}_{2} \mathrm{O}_{3}$ & 6.2 \\
$\mathrm{MgO}$ & 4.9 \\
$\mathrm{~K}_{2} \mathrm{O}$ & 2.1 \\
$\mathrm{Na}_{2} \mathrm{O}$ & 1.2 \\
$\mathrm{TiO}_{2}$ & 0.58 \\
$\mathrm{La} \& \mathrm{Lu}$ & $1<$ \\
\hline
\end{tabular}

Table 2 Physical properties of Abyek clay.

\begin{tabular}{ll}
\hline $\mathrm{G}_{\mathrm{s}}$ & 2.657 \\
$\mathrm{LL}(\%)$ & 36 \\
$\mathrm{PL}(\%)$ & 20 \\
$\omega_{\text {opt }}$ & 18.5 \\
$\left(\gamma_{d}\right)_{\max }$ & 1.82 \\
\hline
\end{tabular}

2011) and the seismic site response and soil-structure interface of seasonally frozen soils (Czajkowski and Vinson, 1980; Di Donna et al., 2016; Zhao et al., 2014; Zhu et al., 2011). Some recent research considers the dynamic properties of soils after freeze-thaw cycles (Zhang and Hulsey, 2015; Zhang and Cui, 2018). The results show that the dynamic shear modulus decreases with increasing number of freeze-thaw cycles and also increasing freeze-thaw cycles results in an increase or no change in the damping ratio (Zhang and Hulsey, 2015; Zhang and Cui, 2018). Elif Orakoglu et al. (2017) used dynamic triaxial tests to investigate the dynamic properties of fine-grained soil mixed with basalt and glass fibers subjected to freezethaw cycles. The results illustrate the dynamic shear modulus of reinforced soil specimens increases with fiber content, moisture content, and mean effective confining stress and decreases with increasing number of freeze-thaw cycles. Simonsen and Isacsson (2001) studied the resilient behavior of three soils during freezing and thawing utilizing both variable and constant confining pressure triaxial testing; at non- freezing temperatures, the variable confining pressure moduli were approximately 45-55 \% lower than the corresponding constant confining pressure moduli.

While many studies have considered the shear modulus and damping ratio of frozen soil, few have been carried out on soils affected by freeze-thaw cycles (Ling et al., 2015; Liu et al., 2010; Orakoglu and Liu, 2017; Zhang and Hulsey, 2015). In addition, some results reflect the dynamic properties of clayey soil under repeated freeze-thaw cycles but few reports the effect of parameters such as loading frequency on the dynamic properties of the soil after these cycles. Therefore, the current study was undertaken to examine the physical changes of clayey soil samples during freeze-thaw cycles and the changes in dynamic properties because of these cycles. The influences of the number of freeze-thaw cycles, mean effective confining pressure, and frequency on the dynamic parameters of the clayey soil were also analyzed.

\section{TEST APPARATUS AND EXPERIMENTAL PROCEDURES}

\subsection{MATERIALS}

Abyek clay, a clayey soil from Abyek city in Iran and classified as CL according to the USCS (ASTM D2487), was employed in the study. This area is one of the cities in Iran which has extreme cold winters. The chemical properties of the soil obtained from $\mathrm{X}$-ray fluorescence (XRF) and X-ray diffraction (XRD) testing and analysis indicate the clay fractions are mostly composed of illite and clinochlore.

The grain size distribution of Abyek clay is presented in Figure 1. Some chemical and physical properties of the soil are presents in Tables 1 and 2, respectively. As shown in Table 2, based on the standard Proctor compaction test, the soil has a maximum dry mass density of approximately $1.8 \mathrm{~g} / \mathrm{cm}^{3}$ at an optimum moisture content (OMC) of $18.2 \%$

\subsection{SPECIMEN PREPARATION AND FREEZE- THAW CYCLES}

Cyclic triaxial tests were conducted on specimens that had been compacted in a mold $70 \mathrm{~mm}$ in diameter and $140 \mathrm{~mm}$ in height by the wet-tamping technique at the $\mathrm{OMC}( \pm 0.5 \%)$ and maximum dry density $( \pm 4 \%)$. The $\mathrm{OMC}$ and maximum dry density are parameters which are usually used in construction projects such as road and railway embankments, landfill liners, backfills of retaining structure and earth dams, so understanding of the dynamic properties of soil in these conditions are important. The wet-tamping technique is the oldest technique which is used for preparing unreinforced and reinforced soil specimens and has been widely used by previous researchers (Behavior and Symposium, 2006; Escribano and Nash, 2015; Flora and Lirer, 2013; Gu et al., 2015; Maleki and Bayat, 2012). The wet- tamping technique can model the soil fabric of 
rolled construction fills and can produce very loose to dense partially saturated specimens. The wet-tamping technique is the best way to obtain a high porosity, through a very low compaction energy combined with an initial soil water content. For specimen preparation, the OMC was added to the soil, which was then left overnight in a sealed plastic bag to achieve a uniform water content in the soil mass. The soil specimens were formed by compacting the soil in four uniform layers with a layer thickness of $\sim 3.5 \mathrm{~cm}$. After compaction, all specimens were covered with plastic wrap to prevent water evaporation. The covered clay specimens were then placed into a digital refrigerator set at $-20 \pm 2{ }^{\circ} \mathrm{C}$ for $6 \mathrm{~h}$ and then at $+20 \pm 2{ }^{\circ} \mathrm{C}$ for $6 \mathrm{~h}$ to establish each freeze-thaw cycle. Six hours is a proportional period after which, the alteration of specimen's height and diameter during freeze and thaw cycles would become constant. These temperatures and time periods are adequate for samples to achieve solid freezing and complete thawing and had been previously used in some research works (Ghazavi and Roustaie, 2010; Qi et al., 2006; Roustaei et al., 2016).

These temperatures are the ones used in some previous research, such as the study carried out by Qi et al. (2004). Six hours is a proportional period after which, the alteration of specimen's height would become constant.

In whole freeze-thaw process, the samples were encased in the mold and the mold provides confining stress around the sample without a change in diameter. Soil specimens were subjected to $0,1,3,6$, and 9 freeze-thaw cycles, during which the weight and height variation in the specimens were recorded. These numbers of cycles were chosen because most soil strength reduction would occur in the early cycles and after 5 to 10 cycles a new equilibrium condition would establish (Ghazavi and Roustaie, 2010).

\subsection{CYCLIC TRIAXIAL TESTS}

Cyclic triaxial test as defined by ASTM D 3999 are usually used to identify the dynamic properties of soil specimens. Since freeze-thaw cycles usually occur at the ground surface, which is not also under the pressure of a thin layer of soil but also in contact with structure foundations, road pavement or railway tracks and their traffic loads, three confining pressures of 100,200 and $300 \mathrm{kPa}$ were adopted for this test. In this study, stress control tests were conducted on an automated system, using a hydraulic actuator while the amount of load, pressure and axial deformation were recorded using a ZEMIC loadcell, SENSYS pressure transducer and LPS-100S sensor, respectively. Figure 2 shows the test setup as well as some samples after the tests.

The recording accuracy of all sensors was $1 \%$ during the tests. Due to the large sample size and the long procedure to saturate fine-grained soils, experiments were carried out on unconsolidated and unsaturated samples with a saturation degree of $0.72( \pm 2 \%)$. Constant cyclic shear stress amplitude loading begins at a small amplitude and gradually increases. Each stage of loading consists of 40 loading cycles. Drainage was not allowed during each stage of loading; the drainage valves were opened before the next stage of loading. The hysteresis loop at the tenth cycle of loading in each stage is used to compute the dynamic properties as it best represents typical seismic loading (Zhang et al., 2005). The shear stress, $\tau$, and the corresponding shear strain, $\gamma$, can be calculated from:

$\tau=\frac{\sigma_{d}}{2}$

$\gamma=\varepsilon_{a}(1+v)$

where $\sigma_{d}$ is the deviator stress, $\varepsilon_{a}$ is the axial strain as measured by a data acquisition system during the cyclic triaxial test, and $v$ is Poisson's ratio. A typical Poisson's ratio of 0.3 was used as suggested by Bowles (Bowles, 1997) for unsaturated clay soil. The shear modulus can be determined from secant shear modulus $\left(G_{s e c}\right.$ or $\left.G\right)$ :

$G_{s e c}$ or $G=\frac{\tau_{c}}{\gamma_{c}}$

where $\tau_{c}$ and $\gamma_{c}$ are the shear stress amplitude and shear strain amplitude, respectively. The material damping ratio $(D)$, which is calculated from the dissipated energy $W_{D}$ versus elastic strain energy $W_{S}$, can be determined for a given hysteresis loop from:

$D=\frac{W_{D}}{4 \pi W_{S}}=\frac{1}{2 \pi} \times \frac{A_{\text {loop }}}{G \gamma^{2}}$

where $W_{D}$ is the energy dissipated in one cycle of loading (the area inside the hysteresis loop) and $W_{S}$ is the maximum strain energy stored during the cycle (the area of the triangle). All the cyclic triaxial tests performed using a series of sinusoidal cyclic stress cycles were imposed on the top platen of tested specimens at a constant frequency of 0.2 or $0.4 \mathrm{~Hz}$.

Table 3 summarizes the details of the triaxial tests used in this study. The shear modulus and damping ratio of the clayey soil in the small-to-large shear strain range $(0.0004-0.1 \%)$ are extracted from the results of these tests.

\section{RESULTS AND DISCUSSION \\ 3.1. EFFECT OF FREEZE-THAW CYCLES ON SOIL POROSITY}

Frost heave is a common result of freeze-thaw cycles in soil due to increasing volumes when freezing and decreasing volumes when thawing. The decrease and increase values are not the same and specimens will not return to their initial volume, so this phenomenon results in changes in soil properties such as a significant decrease in cohesion (Ghazavi and Roustaei, 2013). In this study, three samples were randomly chosen from all of the samples collected and their dimensions were monitored during freeze-thaw cycles. Samples were covered with a plastic wrap after removal from mold in preparation procedure, so the boundaries are free to move. The samples 1 to 3 were 


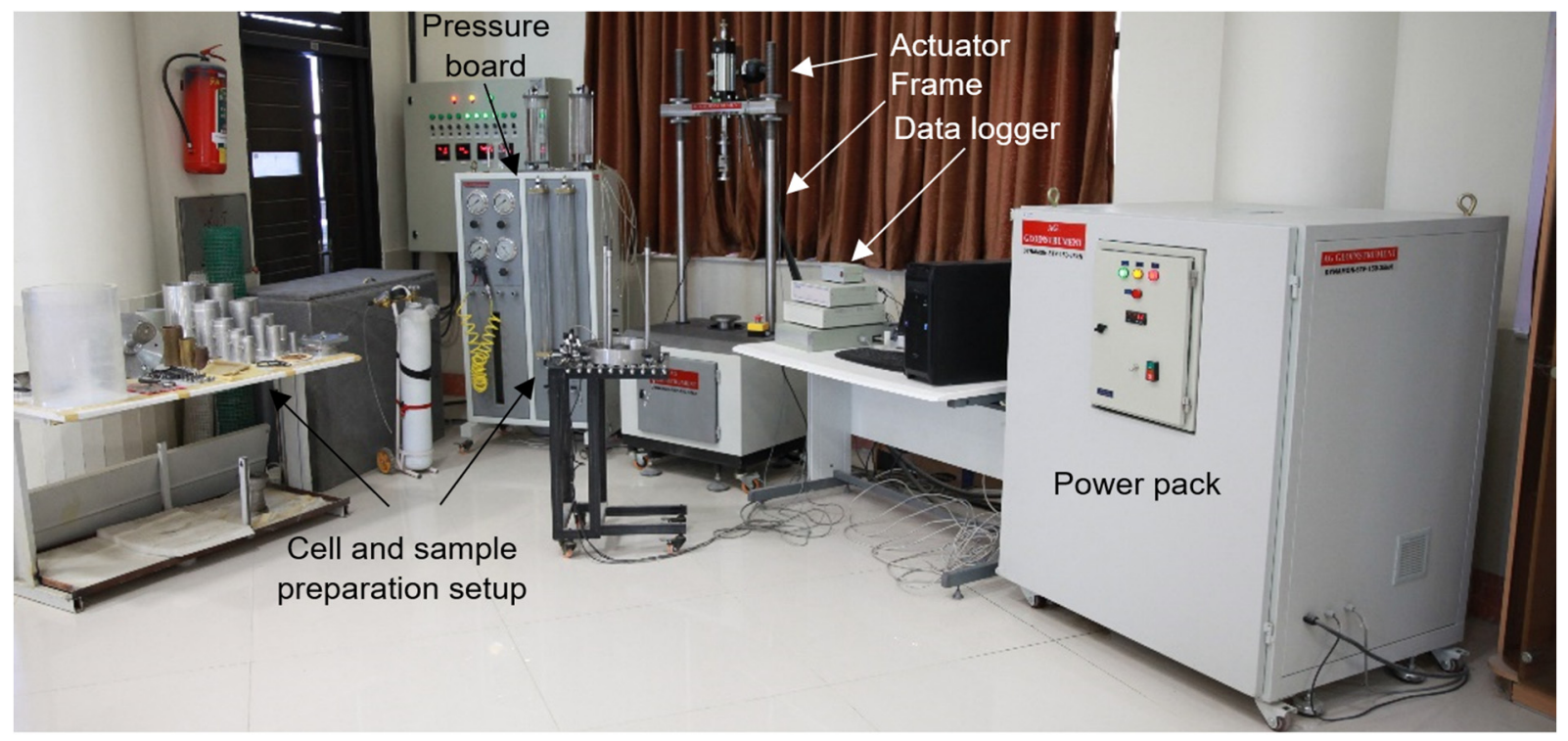

(a)
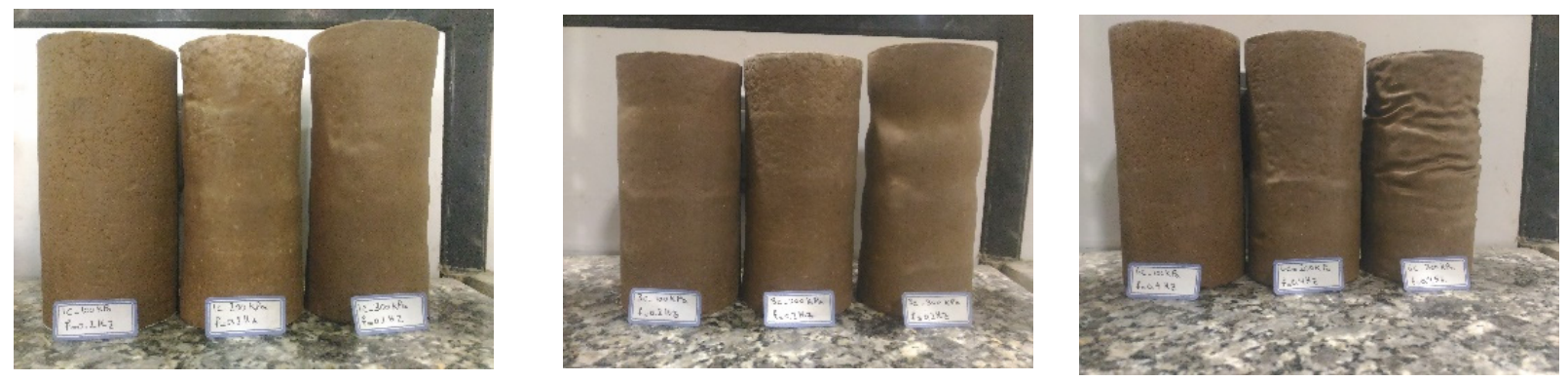

(b)

Fig. 2 a) Cyclic triaxial setup and b) specimens after the test.

Table 3 Summary of the triaxial tests details.

\begin{tabular}{cccc}
\hline $\begin{array}{c}\text { Effective confining } \\
\text { stress }(\mathrm{kPa})\end{array}$ & Loading Frequency & No. of freeze-thaw cycles & No. of triaxial tests \\
\hline \multirow{2}{*}{100} & 0.2 & $0,1,3,6$ and 9 & 10 \\
\hline \multirow{2}{*}{200} & 0.4 & $0,1,3,6$ and 9 & 10 \\
\hline \multirow{2}{*}{300} & 0.4 & 0.2 & $0,1,3,6$ and 9 \\
\hline
\end{tabular}

compacted at water contents of $18.3,18.5$ and $18.6 \%$ with corresponding dry densities of $18,18.2$ and $18.1 \mathrm{kN} / \mathrm{m}^{3}$, respectively. Figure 3 shows the variations of diameter, height, volumetric statin, void ratio and unit weight of these three samples.

In this figure $D_{0}$ and $H_{0}$ are initial diameter and height of the samples while $D_{c}, H_{c}$ are the ones after each cycle. The void ratio after each cycle was calculated according to the amount of volumetric statin while the unit weight was computed using the weight and volume of samples after a cycle. The results show that volumetric strain and void ratio of these three samples increased and their unit weight decreased over the nine freeze-thaw cycles. These changes indicate an increase in the voids between clay particles can be the result of applied load from the ice lenses to the soil particles in the freezing phase and lead to mechanical changes in the soil samples. These curves also indicate that most changes in the physical characteristics of the soil samples occurred during the first six cycles; thereafter, most values became almost constant, consistent with a new equilibrium condition (Bowles, 1997).

\subsection{EFFECT OF FREEZE-THAW CYCLES ON MICROFABRIC STRUCTURE}

Scanning electron microscopy (SEM) has recently been used to investigate the microstructural 


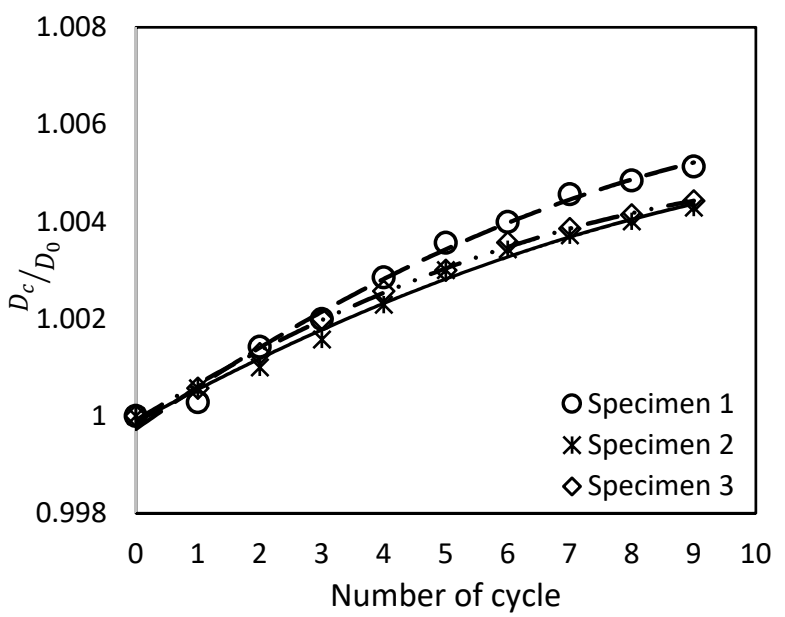

(a)

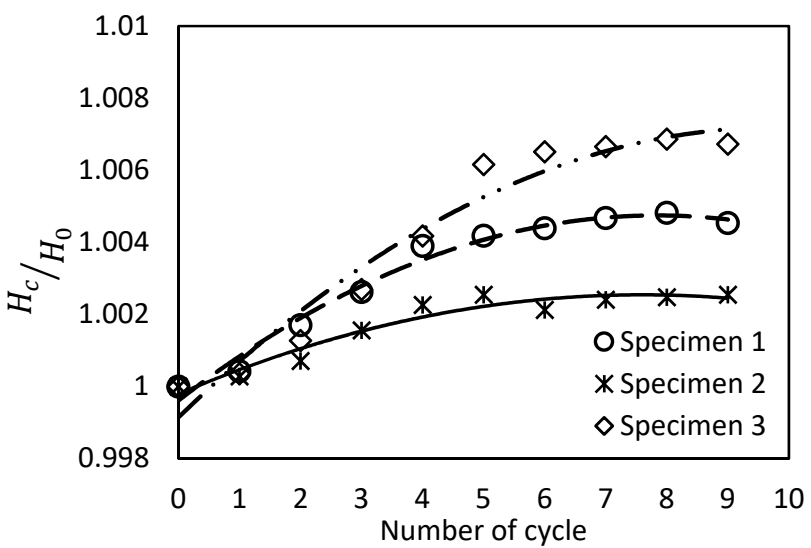

(b)

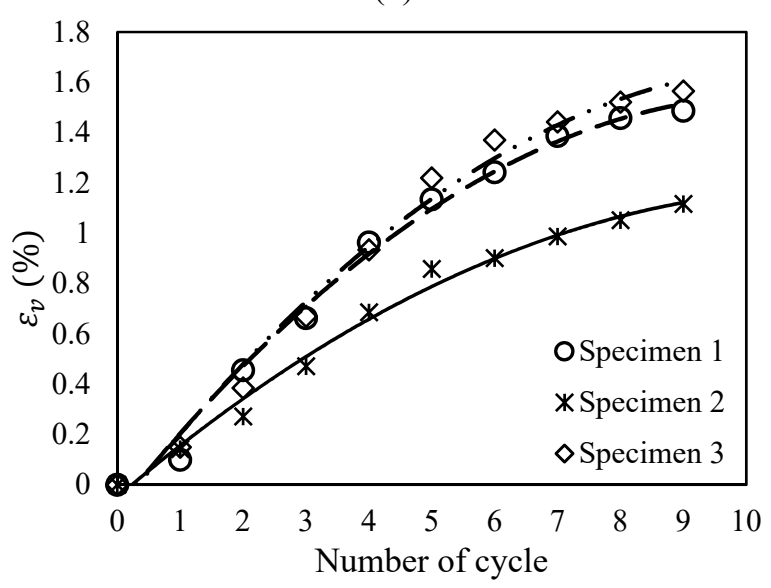

(c)

changes of soil samples after freeze-thaw cycles (Roustaei et al., 2015). Figure 4 shows that the soil fabric before the freeze-thaw cycles was almost smooth with small holes and surface cracks but became rougher and more irregular thereafter. Cracking and spalling are the most common results of freeze-thaw damage in clayey soils. This aligns with the results above that suggest the voids between the clay particles increase due to the formation of ice lenses. The mineral skeleton adjacent to the ice lenses and freezing front underwent appreciable

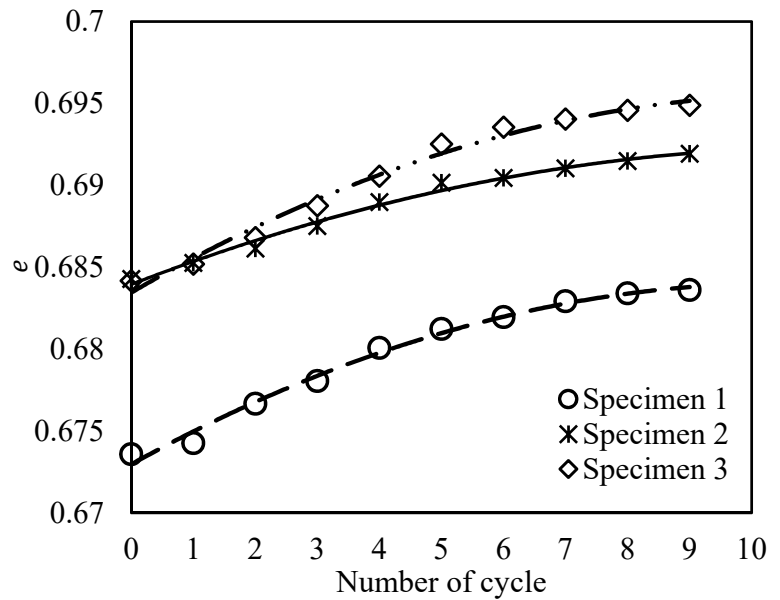

(d)

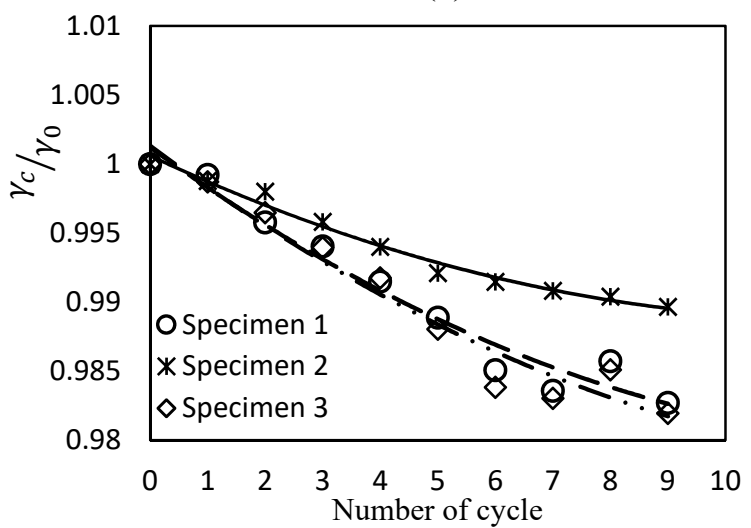

(e)

Fig. 3 Variation in the (a) diameter, (b) height, (c) volumetric strain, (d) void ratio and (e) unit weight of three different samples over nine freeze-thaw cycles.

compression. The compression itself caused by the movement of water during freezing develops a spatial network of channels that provides water for the growing ice lenses (Hohmann-Porebska, 2002). This network of channels left after the thawing of ice crystals is obvious in the SEM images, would increase the soil permeability, and could be the main reason for the increasing trend in the damping ratio. High soil moisture suction developed in the zone of freezing also causes a very large increase in the effective stress in the unfrozen soil immediately adjacent to this zone and could also contribute to the changes in the dynamic behavior of soil samples subjected to repeated freeze-thaw cycles (Pusch, 1979).

\subsection{EFFECT OF FREEZE-THAW CYCLES ON DYNAMIC PROPERTIES OF SOIL}

Figure 5 shows the shear modulus and damping ratio curves of the soil samples under a constant confining pressure of $100 \mathrm{kPa}$, before and after nine freeze-thaw cycles at a constant frequency of $0.2 \mathrm{~Hz}$. 

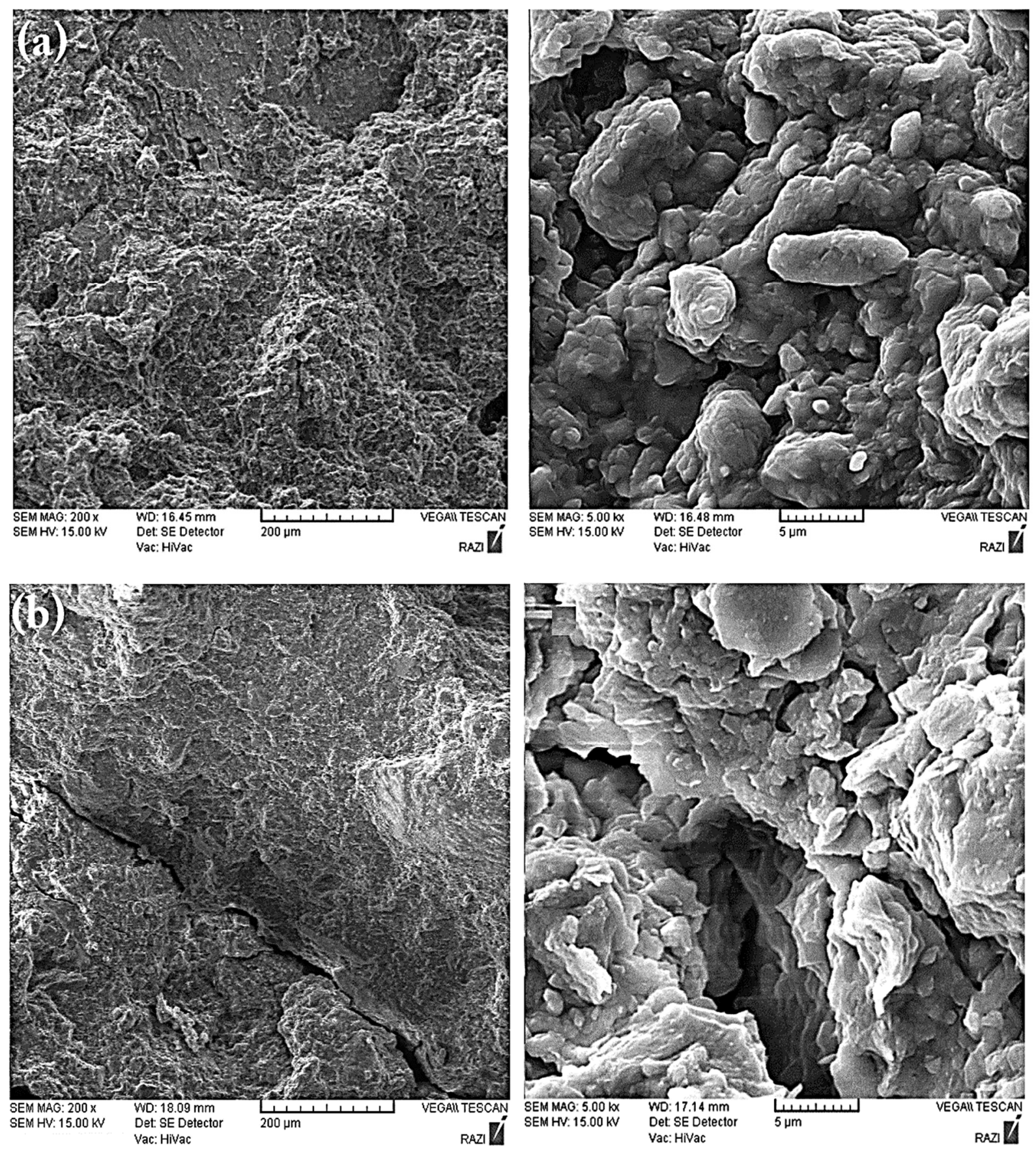

Fig. 4 SEM images of soil specimens (a) before and (b) after nine freeze-thaw cycles at two different scales (left: scale $200 \mu \mathrm{m}$, right: scale $5 \mu \mathrm{m}$ ).

The shear modulus of soil specimens exhibited nonlinear features and degraded sharply as the strain amplitude increased to above $10^{-3} \%$. These results show that the shear modulus decreases with increasing number of freeze-thaw cycles at a given confining pressure and shear strain amplitude, especially at small strains; however, the damping ratio increased as the number of freeze-thaw cycles increased from 0 to 9 . These findings are in agreement with previous experimental results (Wang et al., 2015). Also obvious in the SEM images is that an increase in the number of freeze-thaw cycles causes a significant change in the soil fabric by disrupting the interlocking, which affects the dynamic properties in terms of shear modulus reduction and damping ratio increase. In other words, the soil becomes looser and its void ratio increases after freeze-thaw cycles, which increases the consumption of energy and the damping ratio and decreases the shear modulus and the resistance of soil particles to movement (He and Zhang, 2005). Figure 6 shows the effect of freeze-thaw cycles on the hysteretic displacement-load loop of the specimens obtained from cyclic triaxial tests conducted at a frequency of $0.2 \mathrm{~Hz}$. As shown in the figure, the 

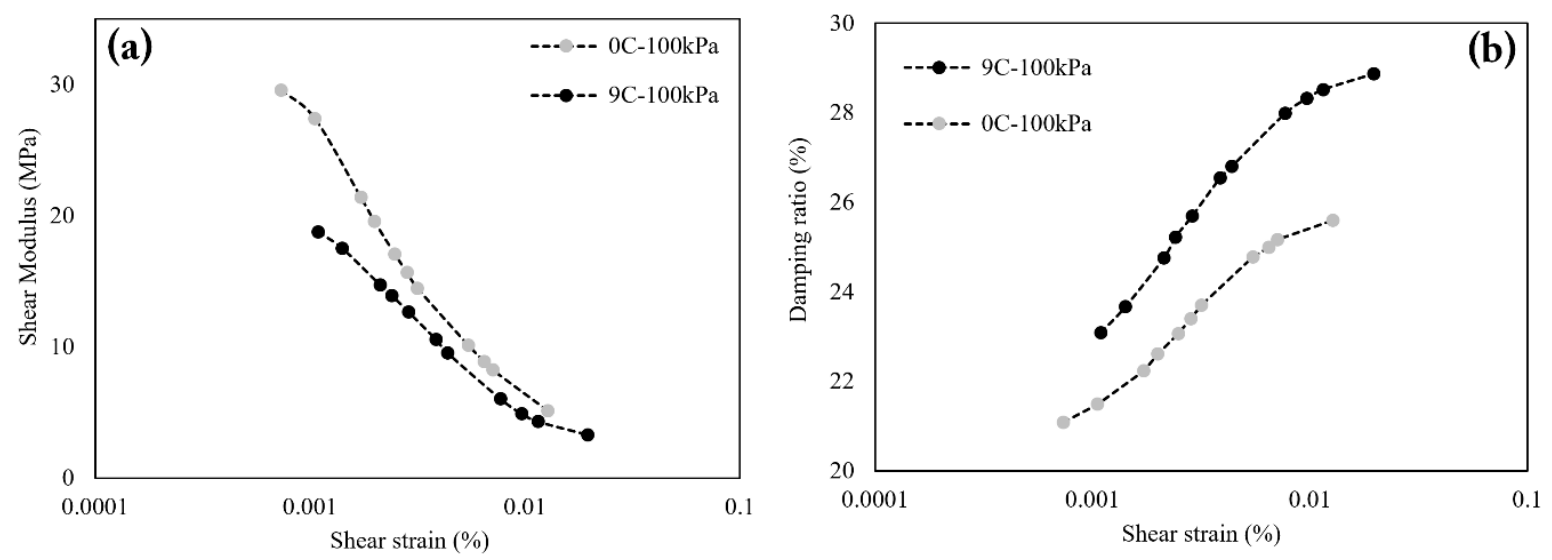

Fig. 5 Variation of (a) shear modulus and (b) damping ratio of soil specimens after nine freeze-thaw.

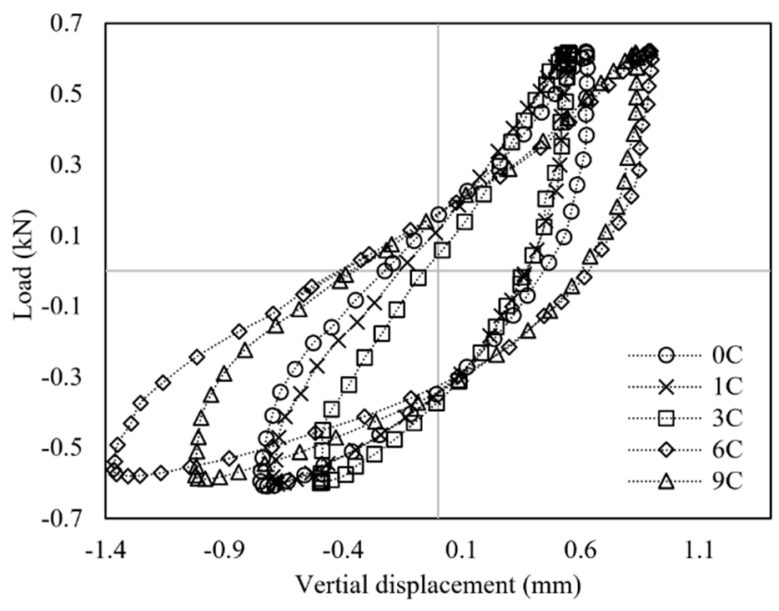

Fig. 6 Effect of number of freeze-thaw cycles in the hysteretic shear stress-shear strain loop under constant confining pressure and cyclic stress ratio.

shear modulus decreases, and the corresponding shear strain amplitude increases with an increasing number of freeze-thaw cycles.

\subsection{EFFECT OF CONFINING PRESSURE ON DYNAMIC PROPERTIES OF SOIL}

The effect of confining pressure on the $G-\gamma$ and $D-\gamma$ curves for the specimens after experiencing nine freeze-thaw cycles are shown in Figure 7. An increase in the confining pressure increases $G$ and decreases $D$ for a given shear strain amplitude. However, the effect on the shear modulus decreases with increasing shear strain amplitude. These findings are in good agreement with previous experimental results (Bayat and Ghalandarzadeh, 2020; Teachavorasinskun et al., 2002).

These results show the effect of the freeze-thaw cycles on the damping ratio of the soil becomes more pronounced as the confining pressure decreases. Each freeze-thaw cycle consists of a freezing phase, in which ice crystals are formed and the soil specimen is subjected to considerable stress and volumetric change. This increases the distance between soil particles and channels develop within the soil skeleton. At higher confining pressures, soil particle rearrangement closes the cracks and fissures produced by the freeze-thaw process and enhances the soil strength (Wang et al., 2017), which would explain the results shown in Figure 7. Moreover, Figure 8 shows the effect of mean effective confining pressure on the hysteretic stress-strain loop of the specimens obtained from cyclic triaxial testing conducted at a frequency of $0.2 \mathrm{~Hz}$ and cyclic stress ratio (CSR) of 0.2. As shown, the shear strain amplitude increases with increasing confining pressure.

\subsection{EFFECT OF LOADING FREQUENCY ON DYNAMIC PROPERTIES OF SOIL}

Figure 9 presents the effect of frequency ( 0.2 or $0.4 \mathrm{~Hz}$ ) on the shear modulus and damping ratio versus shear strain amplitude for specimens subjected to nine freeze-thaw cycles at a confining pressure of 100, 200, or $300 \mathrm{kPa}$. Increasing the loading frequency increases the shear modulus; however, the effect of frequency on damping ratio is not clear. Increasing the loading frequency either increases or decreases the damping ratio depending upon the mean effective confining pressure and number of freeze-thaw cycles.

Previous studies indicate the damping ratio of saturated soils is frequency dependent, where energy dissipation can be attributed to the inelasticity of the soil skeleton and the viscous interaction of fluid in the pore space. Soil skeleton losses dominate at low frequencies, while viscous losses prevail at high frequencies (Moayerian, 2012; Wang et al., 2017). Although the difference between the two frequencies in the current study might not be sufficient to observe any effect on changes in dynamic properties during freeze-thaw cycles, Figure 10 shows that the amount of damping ratio increase after nine freeze-thaw cycles is greater at the higher frequency when the rate of loading and unloading is faster. 

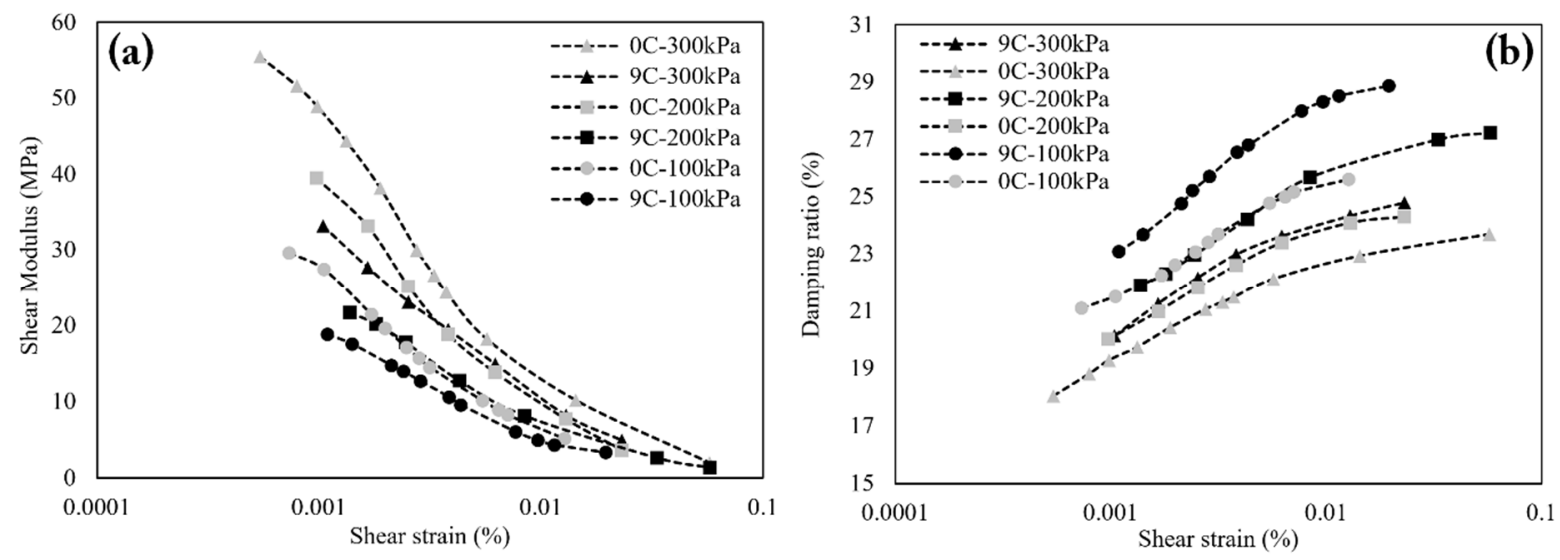

Fig. 7 Variation of (a) shear modulus and (b) damping ratio of soil specimens after nine freeze-thaw cycles under three different confining pressures.

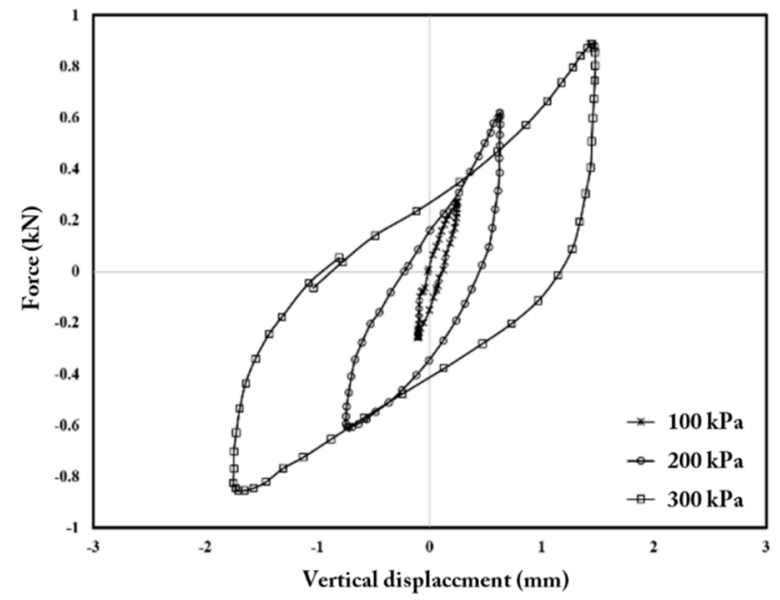

Fig. 8 Effect of confining pressure in the hysteretic shear stress-shear strain loop before any freeze-thaw cycles under a constant CSR.

\subsection{THE PROPOSED MODEL}

The results of the tests indicate that the factors affecting the shear modulus are the shear strain level, effective confining pressure, number of freeze-thaw cycles, and frequency. The following empirical equation is proposed to estimate the shear modulus:

$$
G(M P a)=a_{1} \times \frac{1}{1+\gamma^{a_{2}}} \times\left(\frac{\sigma^{\prime}}{101}\right)^{a_{3}} \times\left(\frac{1}{(1+F Z)^{a_{4}}}\right) \times(1+f)^{a_{5}}
$$

Where $G$ is shear modulus in $\mathrm{MPa}, \gamma$ is shear stain, $\sigma^{\prime}$ is effective confining pressure in $\mathrm{kPa}, \mathrm{FZ}$ is the number of freeze-thaw cycles, $f$ is frequency in $\mathrm{Hz}$, and $a_{1}$ to $a_{5}$ are the fitting parameters which are constant as shown in Table 4. As shown in Figure 11(a), the correlation coefficient between the measured and predicted values of shear modulus is 0.91 which validates the feasibility of the proposed equation. In the current study, the nonlinear least squares method was used for the identification of the fitting parameters.
In the current study, the following equation is also presented to predict the damping ratio as a function of shear strain level, effective confining pressure, and number of freeze-thaw cycles:

$D(\%)=b_{1} \times(1+\gamma)^{b_{2}} \times\left(\frac{101}{\sigma^{\prime}}\right)^{b_{3}} \times(1+F Z)^{b^{4}}$

As shown in Figure 11(b), the proposed equation predicts values relatively well at desired distribution around $\mathrm{y}=\mathrm{x}$ line.

\section{CONCLUSIONS}

Changes in the dynamic properties of cohesive soil induced by freeze-thaw have not received as much attention as other aspects of frozen soil engineering. The current study examined the influence of mean effective confining pressure, loading frequency, and number of freeze-thaw cycles on the dynamic properties of a clayey soil using systematic laboratory tests. After testing specimens through triaxial apparatus, the following results can be concluded:

1. Volumetric measurements and void ratio calculations of the soil samples during freezethaw cycles indicate the samples become looser because the voids between clay particles increase. This phenomenon combined with disruption of the interlocking of soil grains noted in SEM

Table 4 The models parameters.

\begin{tabular}{cc}
\hline Model parameters & Value \\
\hline$a_{1}$ & 31.2 \\
$a_{2}$ & 177 \\
$a_{3}$ & 0.5 \\
$a_{4}$ & 18.6 \\
$a_{5}$ & 18.4 \\
$b_{1}$ & 24.4 \\
$b_{2}$ & 1.80 \\
$b_{3}$ & 0.12 \\
$b_{4}$ & 0.04 \\
\hline
\end{tabular}



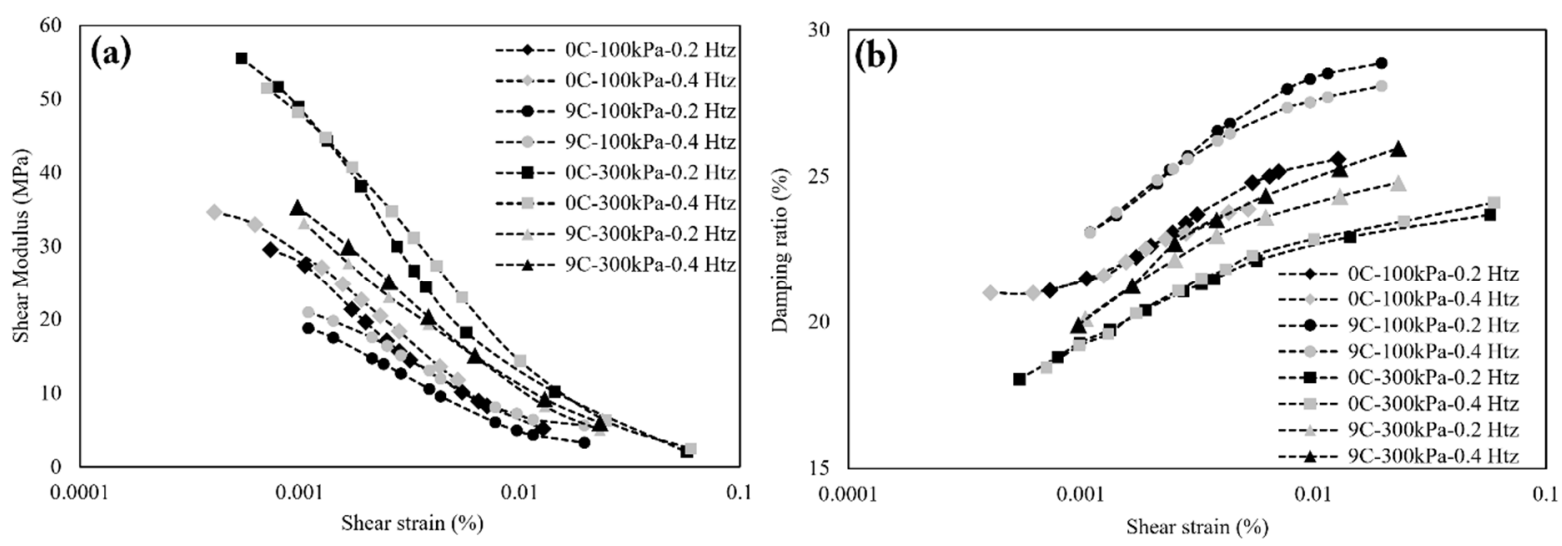

Fig. 9 Variation of (a) shear modulus and (b) damping ratio after nine freeze-thaw cycles in terms of loading frequency.
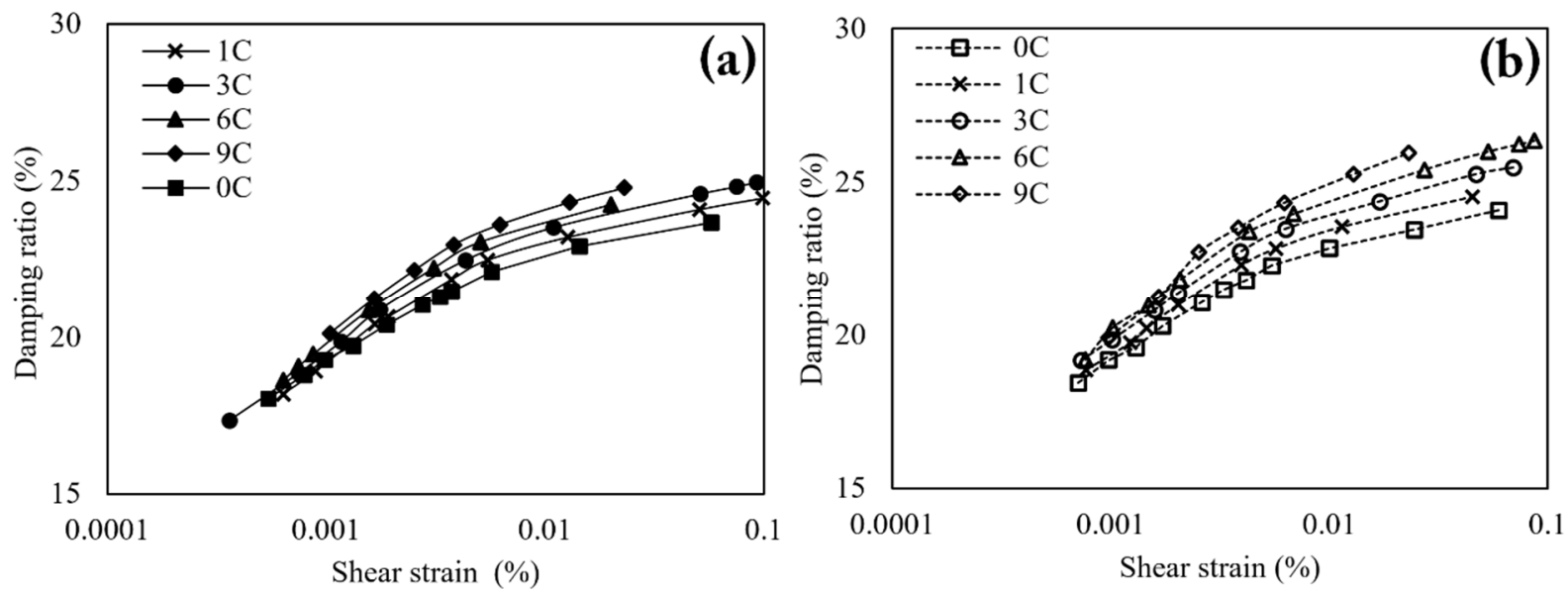

Fig. 10 Variation of damping ratio after nine freeze-thaw cycles for loading frequencies of (a) 0.2 and (b) $0.4 \mathrm{~Hz}$.
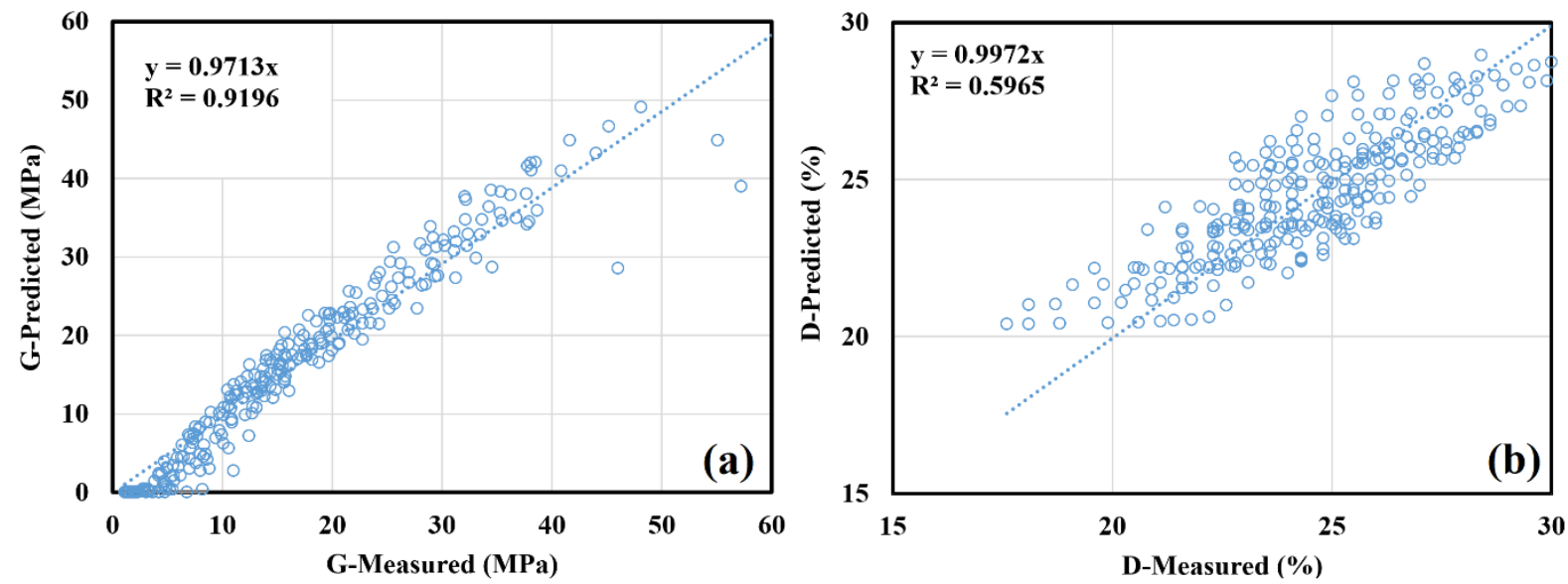

Fig. 11 (a) G-values predicted by Eq. (6) versus measured G-values (b) D-values predicted by Eq. (7) versus measured D-values. 
photos likely results in the change of dynamic properties of the soil.

2. The shear modulus and damping ratio of clay soils are mainly affected by the mean effective confining stress, loading frequency, and number of freeze-thaw cycles. The results of dynamic triaxial tests showed the damping ratio increases and the shear modulus decreases at small and medium strain amplitudes but remains almost unchanged at large strain amplitudes as the number of freeze-thaw cycles increases. An increase in the mean effective confining stress increases the shear modulus because the effect of freeze-thaw cycles decreases as the confining pressure increases. It can be conducted that freeze-thaw cycles are more destructive at the ground surface, which is in contact with structure foundations or road pavement.

3. The results show that an increase in loading frequency increases the shear modulus. Decreasing the mean effective confining stress or increasing the freeze-thaw cycles moves the damping ratio curves upward. However, the effect of frequency on the damping ratio of the clay specimens under various freeze-thaw cycles remains unclear. Increasing the loading frequency increases or decreases the damping ratio depending upon the mean effective confining pressure and number of freeze-thaw cycles. These findings which could result in poor condition of soil mixtures can be used to predict the seismic response analysis of seasonally frozen ground more accurately.

4. This paper describes the development of models to estimate shear modulus and damping ratio for clayey soil from loading and freeze-thaw conditions. Two models (Eqs. 6 and 7) have been developed to predict shear modulus and damping ratio from a collected database that contains 27 tests. The results indicate that the proposed equations can evaluate the shear modulus and damping ratio of clayey soil.

\section{ACKNOWLEDGEMENT}

The authors would like to acknowledge the financial support of the Islamic Azad University of Qazvin of this research project.

\section{REFERENCES}

Bayat, M.: 2020, Universal model forms for predicting the dynamic properties of granular soils. Acta Geodyn. Geomater., 17, 217-227. DOI: 10.13168/agg.2020.0016

Bayat, M. and Ghalandarzadeh, A.: 2020, Modified models for predicting dynamic properties of granular soil under anisotropic consolidation. Int. J. Geomech., 20, 1-15. DOI: 10.1061/(ASCE)GM.1943-5622.0001607

Bayat, M. and Ghalandarzadeh, A.: 2019, Influence of depositional method on dynamic properties of granular soil. Int. J. Civ. Eng., 17, 907-920.

DOI: $10.1007 / \mathrm{s} 40999-019-00412-7$
Behavior, S.S. and Symposium, A.G.: 2006, Soil stressstrain behavior: Measurement, modeling and analysis. Geotechnical Symposium in Roma, March 16-17, 2006. Science and technology, 1-10. DOI: 10.1007/978-1-4020-6146-2

Bowles, J.E.: 1997, Foundation-analysis-and-design-5thEdition-Joseph-E-Bowles.pdf.

Czajkowski, R.L. and Vinson, T.S.: 1980, Dynamic properties of frozen silt under cyclic loading. J. Geotech. Eng. Div., ASCE, 106, 963-980. DOI: 10.1016/0148-9062(81)90792-0

Di Donna, A., Ferrari, A. and Laloui, L.: 2016, Experimental investigations of the soil-concrete interface: Physical mechanisms, cyclic mobilization, and behaviour at different temperatures. Can. Geotech. J., 53, 659-672. DOI: $10.1139 / \mathrm{cgj}-2015-0294$

Dusenkova, I., Stepanova, V., Vecstaudza, J., Lakevics, V., Malers, J. and Berzina-Cimdina, L.: 2013, Rheological properties of Latvian illite clays. Acta Geodyn. Geomater., 10, 459-464. DOI: $10.13168 /$ AGG.2013.0046

Escribano, D.E. and Nash, D.F.T.: 2015, Changing anisotropy of G0 in Hostun sand during drained monotonic and cyclic loading. Soils Found., 55, 974984. DOI: $10.1016 /$ j.sandf.2015.09.004

Flora, A. and Lirer, S.: 2013, Small strain shear modulus of undisturbed gravelly soils during undrained cyclic triaxial tests. Geotech. Geol. Eng., 31, 1107-1122. DOI: $10.1007 / \mathrm{s} 10706-013-9636-4$

Ghazavi, M. and Roustaei, M.: 2013, Freeze-thaw performance of clayey soil reinforced with geotextile layer. Cold Reg. Sci. Technol., 89, 22-29. DOI: $10.1016 /$ j.coldregions.2013.01.002

Ghazavi, M. and Roustaie, M.: 2010, The influence of freeze-thaw cycles on the unconfined compressive strength of fiber-reinforced clay. Cold Reg. Sci. Technol., 61, 125-131. DOI: 10.1016/j.coldregions.2009.12.005

Gu, X., Yang, J., Huang, M. and Gao, G.: 2015, Bender element tests in dry and saturated sand: Signal interpretation and result comparison. Soils Found., 55, 951-962. DOI: 10.1016/j.sandf.2015.09.002

Hanumantharao, C. and Ramana, G.V.: 2008, Dynamic soil properties for microzonation of Delhi, India. J. Earth Syst. Sci., 117, 719-730. DOI: $10.1007 / \mathrm{s} 12040-008-0066-2$

Hardin, B.O. and Drnevich, V.P.: 2002, Shear modulus and damping in soils: Design equations and curves. Geotechnical Special Publication, 98, 1459-1484.

He, J.Q. and Zhang, J.S.: 2005, Experimental study on dynamic properties of soft soil treated with lime under cyclic loading. J. Hunan Univ. Sci. Technol., 20, 5863.

Hohmann-Porebska, M.: 2002, Microfabric effects in frozen clays in relation to geotechnical parameters. Appl. Clay Sci., 21, 77-87.

DOI: 10.1016/S0169-1317(01)00094-1

Jafarian, Y., Haddad, A. and Javdanian, H.: 2014, Predictive model for normalized shear modulus of cohesive soils. Acta Geodyn. Geomater., 11, 89-100. DOI: $10.13168 /$ AGG.2013.0057

Khan, Z., El Naggar, M.H. and Cascante, G.: 2011, Frequency dependent dynamic properties from resonant column and cyclic triaxial tests. J. Franklin Inst., 348, 1363-1376. DOI: 10.1016/j.jfranklin.2010.04.003 
Kokusho, T.: 1980, Cyclic triaxial test of dynamic soil properties for wide strain range. Soils Found., 20, 4560. DOI: $10.3208 /$ sandf1972.20.2_45

Konrad, J.M.: 1989, Physical processes during freeze-thaw cycles in clayey silts. Cold Reg. Sci. Technol., 16, 291-303. DOI: 10.1016/0165-232X(89)90029-3

Lin, B., Zhang, F., Feng, D., Tang, K. and Feng, X.: 2018, Dynamic shear modulus and damping ratio of thawed saturated clay under long-term cyclic loading. Cold Reg. Sci. Technol., 145, 93-105.

DOI: 10.1016/j.coldregions.2017.10.003

Ling, X.Z., Zhang, F., Li, Q.L., An, L.S. and Wang, J.H.: 2015, Dynamic shear modulus and damping ratio of frozen compacted sand subjected to freeze-thaw cycle under multi-stage cyclic loading. Soil Dyn. Earthq. Eng., 76, 111-121.

DOI: $10.1016 /$ j.soildyn.2015.02.007

Liu, J., Wang, T. and Tian, Y.: 2010, Experimental study of the dynamic properties of cement- and lime-modified clay soils subjected to freeze-thaw cycles. Cold Reg. Sci. Technol. 61, 29-33.

DOI: 10.1016/j.coldregions.2010.01.002

Maleki, M. and Bayat, M.: 2012, Experimental evaluation of mechanical behavior of unsaturated silty sand under constant water content condition. Eng- Geol., 141142, 45-56. DOI: 10.1016/j.enggeo.2012.04.014

Moayerian, S.: 2012, Effect of loading frequency on dynamic properties of soils using resonant column. Civil Engineering Master Thesis, 112.

Ng, I.T., Yuen, K.V. and Lao, N.K.: 2016, Probabilistic characterization of cyclic shear modulus reduction for normally to moderately over-consolidated clays. J. Earthq. Eng. Eng. Vib., 15, 495-508. DOI: $10.1007 / \mathrm{s} 11803-016-0339-8$

Orakoglu, E., Liu, J., Niu, F., Elif Orakoglu, M., Liu, J. and Niu, F.: 2017, Dynamic behavior of fiber-reinforced soil under freeze-thaw cycles. Soil Dyn. Earthq. Eng., 101, 269-284. DOI: 10.1016/j.soildyn.2017.07.022

Orakoglu, M.E. and Liu, J.: 2017, Effect of freeze-thaw cycles on triaxial strength properties of fiberreinforced clayey soil. KSCE J. Civ. Eng., 21, 21282140. DOI: 10.1007/s12205-017-0960-8

Pusch, R.: 1979, Unfrozen water as a function of clay microstructure. Developments in Geotechnical Engineering, 26, 157-162.

DOI: 10.1016/B978-0-444-41782-4.50018-X

Qi, J., Vermeer, P.A. and Cheng, G.: 2006, A review of the influence of freeze-thaw cycles on soil geotechnical properties. Permafr. Periglac. Process., 17, 245-252. DOI: $10.1002 / p p p .559$

Renliang, S., Yongwei, S., Liwei, S. and Yao, B.: 2019, Dynamic property tests of frozen red sandstone using a split hopkinson pressure bar. Earthq. Eng. Eng. Vib., 18, 511-519. DOI: 10.1007/s11803-019-0518-5

Roustaei, M., Eslami, A. and Ghazavi, M.: 2015, Effects of freeze-thaw cycles on a fiber reinforced fine grained soil in relation to geotechnical parameters. Cold Reg. Sci. Technol., 120, 127-137. DOI: 10.1016/j.coldregions.2015.09.011

Roustaei, M., Ghazavi, M. and Aliaghaei, E.: 2016, Application of tire crumbs on mechanical properties of a clayey soil subjected to freeze-thaw cycles. Sci. Iran., 23, 122-132. DOI: 10.24200/sci.2016.2103

Senetakis, K. and Payan, M.: 2018, Small strain damping ratio of sands and silty sands subjected to flexural and torsional resonant column excitation. Soil Dyn. Earthq. Eng., 114, 448-459.

DOI: $10.1016 /$ j.soildyn.2018.06.010

Simonsen, E. and Isacsson, U.: 2001, Soil behavior during freezing and thawing using variable and constant confining pressure triaxial tests. Can. Geotech. J., 38, 863-875. DOI: 10.1139/t01-007

Szostak-Chrzanowski, A. and Chrzanowski, A:, 2014, Study of natural and man-induced ground deformation in Mackenzie delta region. Acta Geodyn. Geomater., 11, 117-123. DOI: 10.13168/AGG.2013.0060

Teachavorasinskun, S., Thongchim, P. and Lukkunaprasit, P.: 2002, Shear modulus and damping of soft Bangkok clays. Can. Geotech. J., 39, 1201-1208.

DOI: $10.1139 / \mathrm{t} 02-048$

Vucetic, M. and Mortezaie, A.: 2015, Cyclic secant shear modulus versus pore water pressure in sands at small cyclic strains. Soil Dyn. Earthq. Eng., 70, 60-72. DOI: 10.1016/j.soildyn.2014.12.001

Wang, D.Y., Zhu, Y.L., Peng, W.W., Zhao, S.P. and Li, H.P.: 2003, Measurement of dynamic parameters of frozen soil by ultrasonic techniques. Arlis.

Wang, M., Meng, S., Sun, Y. and Fu, H.: 2018, Shear strength of frozen clay under freezing-thawing cycles using triaxial tests. Earthq. Eng. Eng. Vib., 17, 761769. DOI: $10.1007 / \mathrm{s} 11803-018-0474-5$

Wang, R., Zhu, D., Liu, X. and Sima, J.: 2015, Monitoring the freeze-thaw process of soil with different moisture contents using piezoceramic transducers. Smart Mater. Struct., 24, 057003.

DOI: $10.1088 / 0964-1726 / 24 / 5 / 057003$

Wang, Y., Benahmed, N., Cui, Y.J. and Tang, A.M.: 2017, A novel method for determining the small-strain shear modulus of soil using the bender elements technique. Can. Geotech. J., 54, 280-289.

DOI: $10.1139 / \mathrm{cgj}-2016-0341$

Zhang, Y. and Hulsey, J.L.: 2015, Temperature and freezethaw effects on dynamic properties of fine-grained soils. J. Cold Reg. Eng., 29.

DOI: 10.1061/(ASCE)CR.1943-5495.0000077

Zhang, Z.L. and Cui, Z.D.: 2018, Effect of freezing-thawing on dynamic characteristics of the silty clay under K0consolidated condition. Cold Reg. Sci. Technol., 146, 32-42. DOI: 10.1016/j.coldregions.2017.11.009

Zhao, L., Yang, P., Wang, J.G. and Zhang, L.C.: 2014, Impacts of surface roughness and loading conditions on cyclic direct shear behaviors of an artificial frozen silt-structure interface. Cold Reg. Sci. Technol., 106107, 183-193.

DOI: 10.1016/j.coldregions.2014.07.009

Zhao, L., Yang, P., Zhang, L.C and, Wang, J.G.: 2017, Cyclic direct shear behaviors of an artificial frozen soil-structure interface under constant normal stress and sub-zero temperature. Cold Reg. Sci. Technol., 133, 70-81. DOI: 10.1016/j.coldregions.2016.10.011

Zhu, Z.-Y., Ling, X.-Z., Wang, Z.-Y, Lu, Q.-R, Chen, S. -J, Zou, Z.-Y. and Guo, Z.-H.: 2011, Experimental investigation of the dynamic behavior of frozen clay from the Beiluhe subgrade along the QTR. Cold Reg. Sci. Technol., 69, 91-97.

DOI: $10.1016 /$ j.coldregions.2011.07.007 